\title{
The key role of sport for development and peace in the world
}

\author{
Niels de Fraguier \\ University of Physical Education, Hungary
}

\begin{abstract}
"Sport has the power to change the world." This quote from Nelson Mandela followed by the story of South Africa and his rugby team is undoubtedly one of the best examples that sport is a powerful soft power tool to promote peace and help to solve difficult diplomatic situations and create cohesion in local communities. It will be needed to increase and improve the using of sport as a tool to resolve conflicts and crisis. The choice of the relationship between Sport and Social Development as subject permit to think and understand the role and the goals of the International organizations in the project creation gait. This presentation aims at thinking about the future of the international institutions after the closure of the United Nations Office on Sport for Development and Peace and gives some recommendations linked with this paper findings. This new situation is, according to the United Nations (UN), the logical next step but it includes some risks about the aim of the International Olympic Committee (IOC) in the area of social development. It will be demonstrated that the work of UN was effective to create a solid base for sports projects and massive credibility for international institutions and government. New working methods will be develop for projects including a new form of actions involving the IOC for its influence but also the social actors of United Nations to keep in mind the Sustainable Development Goals' (SDG's).
\end{abstract}

Keywords: Sport for Social Development and Peace, International Organisations, Youth Education.

\section{INTRODUCTION}

The influence and the potency of Sport are today used by many organizations from the States to the Non-Governmental organizations to develop skills as well as a peacebuilding and a peacekeeping implemented in the most dramatic situations over the world (refugee crisis, wars, conflicts...). The sport used as a tool is called "Sport for Development and Peace" (SDP) and it is very important to insist on the "for" which is the key of this action. The official definition of sport by the IOC is a "competition that leads to the award of medals" in opposite of "all forms of physical activity that contribute to physical fitness, mental well-being and social interaction, such as play, recreation, organized or competitive sport, and indigenous sports and games”, which is the definition of United Nations Office on Sport for Development and Peace (UNOSDP). As we can see there is a huge difference between these two meanings, it is about the aim of sport which is a form of victory for the IOC and a promotion of well-being for the United Nations. These definitions illustrate the two types of sport organisations which are most of the time working conjointly despite their different goals. In our current society the place of Sport is growing up and that since the last decades because of the increasing interest of people for competitions but on the other hand because of the impact of sport in development projects. With the actual emergency situations all over the world, the sport is progressively used to create cohesion and solve problems with a lowcost and flexibility characteristics.

\footnotetext{
${ }^{1}$ On September, $25^{\text {th }}$ of 2015 , the UN countries adopted 17 goals to eradicate poverty, protect the planer and reduce the inequalities. The aim is to reach this goals until 2030.
} 
Can we really maintain that sport is the optimum way to develop peace in emergency situations? This article will concentrate on the role of the United Nations and the International Olympic Committee in the field of Sport for Development.

\section{MATERIALS AND METHODS}

To study the case of UNOSDP a secondary research method was used (qualitative approach) with books, texts and information from different official sources as the UN reports. This research was conducted with some key documents about leverage to develop funding and to promote social inclusion through sport during major sports events but also about the relation between Sport; developed together for social inclusion actions. These documents from different organization and authors were helpful to have diverse opinions and facts about this global topic and allowed to see the evolution and innovations linked to this field. This report was carried out by Niels de Fraguier during the year 2017. Different main actors were interviewed as Fred Colter who has been involved in different researches and publications about Sport for Social Development, and Peace and who is now an expert about this area. Some other professionals invested in this specialty of Social Development were also participating in some interviews as Non-governmental organizations managers as well as government officers. These interviews were an important complement of the main research to find precisions, concrete cases, in addition to having different opinions. The confrontation of these opinions and the research of similarities between the different projects and their respective impact allowed a better understanding of the situation and the different limits of the current and future system. These interviews were conducted on Skype and face to face meetings with structured questions related to the definition of Sport for social development. The contributors of this field and their power of action as well as the limits and challenges that the Non-Governmental Organisations and governmental organizations are facing. These interviews took place during different sessions in different phases of the project. The study was also based on European projects taking place in different countries (Hungary, Bulgaria) related to the field of sport and social inclusion. The ASPIRE project was also a very useful reference to lead this investigation and get more information. This project aims at creating a training module to help the integration of refugees in Europe on the horizon 2019 and is directly linked with different Olympic Committees.

\section{RESULTS}

This study was carried during the transition period between the two major international organizations the United Nation Office on Sport for Development and Peace and the International Olympic Committee. After different hypothesis related to the future of the field of Sport for Social Development (SDP) in an International level, it appears that the new responsibility of the IOC comport some risks for the balance in the area of SDP in the next years like the lack of financial independence and the proximity to the sponsors and media. This interdependence between big companies and International organizations compromise the transparency and the interests of the social aspect. Furthermore, the power of the IOC is reduced compared to the UN which had an equal status with the states, this point is very important to understand the ability of these organisations to take important decision which will impact a majority of citizens or only a few. It's important to notice the work of the United Nations in the past 16 years in order to create a dedicated topic for the social development and launch a dynamic to develop it with a flexible 
and cost-effective tool to promote peace was really efficacious. Moreover, the actions of this office were helpful for broadening the possibilities of involvement for NGO's but also volunteers. The new IOC commission is still young and will have to show its power and motivation to reach the Sustainable Goals in 2030. It is also important to mention that the dynamic launched by the UNOSDP was fruitful with the launch of new initiatives including the most influential companies, governments, and intergovernmental organizations with for instance the Centre for Sport \& Human Rights.

\section{DISCUSSION}

\section{Sport for Development: How to use sport as a tool?}

To introduce the subject, it should make clear to define sport for development programmes which aims to create a positive help especially for young generations with the transmission of respect values, abilities and self-confidence thanks to the generation of models and status which are helping the learners. Sport permits to develop cohesion and decrease the violence inside the communities. The projects linked with Sport and Social development also allow to play a fundamental role of an influencer in unstable places and can be explained by a conceptual framework (Fred Coalter's 2009). First, there are the "Plus sport" organizations which are working with the sport as a tool to have resulted in their objectives (without sports link). In the other side, organizations like the United Nations Office for Sport and Development (UNOSDP) is working with the "Sport Plus" methodology which consists to work in order to facilitate the accessibility of sport and are teaching some skills about health, education.

Social development provides education with a transmission of knowledge and experiences which will allow the learners to react differently in their daily life. This education can exist in three forms: Education FOR Sport, Education BY Sport and Education THROUGH Sport. The Education FOR Sport leads the learners to achieve the goal of success in a competitive way. In the case of the Social Development it will be interested to describe the Education BY and THROUGH Sport. Firstly, the Education BY Sport means that Sport is used for a cause which aims at promoting well-being and Public Health with a functional approach. The functional approach is based on the human consciousness which is the beliefs, attitudes and how each person conducts himself in the society. The European movement called "Now we Move" ${ }^{2}$ initiated by the International Sport and Culture Association aims at promoting all of the participation of sport activities and is one of the most famous examples in this type of education.

Secondly, the Education THROUGH Sport (ETS) aims to help the learners to develop themselves with social skills in order to facilitate their inclusion, improve the cohesion of the society and develop the feeling of citizenship and the affiliation of a group. This form of Education works with an Existential and Socio-cultural approach which means that concrete cases with the identification of each identity are using in order to share experiences and learn from the others. This process called Non-Formal Education ${ }^{3}$ makes sense because it gives freedom to all of the participants to give their opinions and share their values but also taking the full responsibility for their opinion. It helps them to learn key competences of groups and individuals on order to contribute to their personal development and their social transformation. The Youth Leadership

\footnotetext{
${ }^{2}$ Campaign launched in 2012 to raise awareness of the benefits and promote sport and physical activity all around Europe.

3 "Refers to any planned programme of personal and social education for young people to improve a range of skills and competencies outside the formal educational curriculum”, COMPASS, A Manual on Human Rights Education for Young People, Council of Europe, 2002
} 
Program ${ }^{4}$ which was developed by UNOSDP with the implication of young people from disadvantaged areas is an example of this education with many activities organised to improve the social skills of the participants.

\section{United Nations Office on Sport for Development and Peace: History of an intergovernmental organization}

Created in February 2001 by Kofi Annan the United Nations Office for Sport and Development (UNOSDP) based in Geneva had the mission to advocate the usage of sport for peace and also facilitate and coordinate some actions to help the stakeholders and states to create projects about sport. Sport becomes each year more and more powerful and a way to promote the strengths of States with huge competition to organize major sports events and have the opportunity to promote national culture and expertise. Since the United Nations Resolution 58/555, the sport has been considered as a tool for development and peace in the Olympic movement, but the creation of UNOSDP was the next step of this idea of using sport without competition and with engagement in the education of disadvantaged people. The project target was to reach the Sustainable Development Goals about poverty reduction, education, conflict resolution, gender equality, helping and integrate disable persons and promoting peace. The work of UNOSDP was linked with every sports sectors from the private sector, media to the National sport organizations which means that it covered a large space in the Sport area. The strength of UNOSDP was to work with all of the sectors in sport and manage private and public relations with the most important stakeholders in the Worldwide Sport organizations. Related to this influence, the concept of Sport is considered by the United Nations as a fundamental right for all people, and it includes all forms of physical activity. In May 2017, the UN Secretary-General Antonio Guterres has announced that the UNOSDP has closed. This decision was rapid and unexpected by most of the stakeholders and organizations. Following this decision, the UN secretary has announced the opening of a new commission managed by the International Olympic Comity (IOC) which is called "IOC Public Affairs and Social Development through Sport". In the past, the United Nations and more precisely the UNOSDP used to work with the IOC and develop some common projects and meetings.

\section{United Nations Office on Sport for Development and Peace: goals are achieving and legacy}

It appears interesting to study more precisely the case of the UNOSDP in the last sixteen years in order to learn from mistakes and successes in this specific field. As explained before, this area is progressing faster since the 2000's and can be explained by the emergence of UNOSDP and new Non-Governmental Organisations (NGO's).

After the closure of UNOSDP most of the reactions were negative and the Consultative Committee of the Enlarged Partial Agreement on Sport (EPAS) ${ }^{6}$ was surprised and said that "this decision sends a problematic message" about the role of the sport in our civil society and the initial objective to keep in mind the 2030 Sustainable Development Agenda ${ }^{6}$. This office linked with the United Nations was the most famous inter-governmental organization which was promoting and recommending sport strategies in an international level, and the decision made by the UN former secretary represent a stoppage of the dynamic of the topic. The influence of this office was important because of the relations with 193 member states all around the world, and this

\footnotetext{
${ }^{4}$ Program lead by the UNOSDP to involve youngsters from disadvantaged communities with theoretical and practical training to improve their social skills.

${ }^{5}$ On November $3^{\text {rd }} 2003$, the UN adopted his resolution which aims at promoting "education, health, development and peace" linked with the International Day of Sport (6 April) and the concept of Sport for Peace and Development.

${ }^{6}$ EPAS is providing a platform which help the dialogue between NGO's, sport federations and public authorities.
} 
possibility to create global projects will be not as easy as before in the next years. The UNOSDP created some events as in 2005 the International Year of Sport and Physical Education (IYPSE) to promote peace and sport through leisure activities which involved 125 UN Member States, the International Day of Sport for Development and Peace every 6 April since 2013. This is two important dates because of their worldwide impact linked with many events organized by most of the countries and the international organizations like the International Paralympic Committee. The impact of the IYPSE was important and offered to the UN the possibility to gather more than 100 international and 1000 local projects all over the world (conferences, summits, training...). We can use the example of the creation of tasks forces as Group of Friends $(\mathrm{GoF})^{7}$, the involving of the private sector with actions managed by the federations and private companies; all of these initiatives were created a dynamic beyond the United Nations with the emphasizing of the notion of "sport for all" in all of the sectors with new partnerships. Some others projects were running by the UNOSDP as the funding and the endorsement of associations and NGO's which were contributing to the development of Sport programmes. This financial help permits to develop and create NGO's in the area which was creating a positive dynamic with more and more actions all around the world.

Despite the strengths of the United Nations Office on Sport for Development and Peace, the past shows that some weaknesses compromised the future of the inter-governmental organization. The main goal was to use sport to reach the 2030 Agenda Sustainable Development Goals in order to develop the social sport sector and its dynamic. The decision to stopped the work of this office comes up 13 years before the target of the United Nations and leave a gap in the worldwide peace and development actions. As writing in the UNOSDP website, "sport has proven to be a cost-effective and flexible tool in promoting peace and development peace objectives," and this is undoubtedly the most crucial point in the SDP characteristics. Linked with these specificities, it appears difficult to understand this decision to stop the development of a powered topic instead of increasing the impact of the decisions and the international commitment. The specific role of the UNOSDP between actors of public and private sectors was needed and it will become a problematic situation with the management of all of the stakeholders which have different interests and purposes.

The action of UNOSDP as a policymaker in the area of sport development can also be criticized about the lack of adaptation in post-conflict places with bruises persons. As every policy, the decisions have an impact on the populations, and even if the first goal is to help them, some undesirable effects are impacting the local communities. Concerning this idea, it is interesting to talk about the neo-colonialism which is defined as the influence of the use of economy, political, cultural and other actions linked with developing countries or specific zones of the world where the past leave a trace. Operate in a specific context with cultural, social and political specificities include the history of the country with the legacy of colonization particularly in African countries. This point can be a general critic to all of the decision makers including the IOC which takes the responsibility of the UNOSDP with a new commission under the responsibility of Thomas Bach.

\section{The new commission of IOC: Public Affairs and Social Development through Sport}

The new commission called Public Affairs and Social Development Through Sport is under the responsibility of the IOC and aims at devising new strategies to advocate the integration of physical activity in national level policies but also advise about all of the strategies linked with the private and the public sectors including the NGO's, foundations and partners. This new attribution took effect in May 2017. It can also be interpreted as a continuity because of the earlier

\footnotetext{
${ }^{7}$ Community of international organizations and countries in the sport field which are facilitating the dialogue between the different members of $\mathrm{UN}$ in order to integrate sport in their strategies and policies.
} 
cooperation between the Olympic organization and the UN since the beginning of the UNOSDP. Since 2001 and the creation of the UNOSDP, the UN office used to work linked with the IOC with for instance the first UN-IOC forum in 2010 in Lausanne which was the first official forum about sport policies with those two organizations. This new step in the history of SDP seems surprising because the economic partners and sponsors of the IOC which are influencing the strategies and the project development by their advice but also by their financing. Samsung and Coca-Cola have each paid more than 120 million of dollars to be "global partner" of the IOC and the last Olympic Games in Rio (2016): those large sums of money illustrate the pressure which is exerted in the organisation and also shows the difficulty that they will have in the future to use the money in non-profit projects. This control by some of the biggest companies in the world is due to the elite level and the worldwide impact of the Olympic events. The domain of Olympic Games is looking for competition, medals and records which is the opposite of the SDP and this conflict seems paradoxical. IOC is well advised to promote elite sport because of the Olympic spirit with the value of "excellence" which means the high level. The positive aspect in this analysis is that the IOC has the financial resources (thanks to the sponsors) to fund social projects, but the complex procedure will be to convince the sponsors and donors to use also sport as a tool for everyone and not just the elite. The case of the Olympic Refugee Team which was competing in Rio with ten athletes from all over the world show that the IOC is involved in the social sector. Even if this example is linked with the high level of competition, it shows that the IOC is working with the major issues: since 2010 the IOC has provided more than USD 1.6 million in support of United Nations Refugee Agency (UNHCR). The Olympic organization is famous in the area of sport, and certainly one of the most powerful in the domain of competitive sport but its partners are mostly Federations and National Olympic Committees (NOC) what is restricted its possibilities to take worldwide decisions linked with States. This is problematic for the reason that most of the programs of the UNOSDP were based in international cooperation between States with International Agreements. Transmit the responsibility to the IOC is certainly a huge challenge which can be disturbing also because of the past of the organization with many affairs of corruption, scandals and affairs of drugs with athletes, the future of the commission appears to be a long track and will imply many modifications in IOC structure and decisions.

\section{CONCLUSION}

This research aimed to understand the role of the Sport as a tool for Social Development in our society with all the challenges which are included. Many initiatives born since the promotion of sport as a tool by the United Nations in 2003 included the creation of new programmes but also the development of new NGO's and International projects. The creation of the UNOSDP leave a strong legacy, and it will be essential to use it to create a sustainable project in this area. The IOC is now in charge of the topic, but all of the actors will have to work together to be powerful, effective and have the opportunity to influence the states to have a real impact.

Following the reasoning that the sponsors and donors are participating to the IOC events in order to promote their products and create a corporate image, the way to follow should be to promote the responsible actions of these brands and use their financing to develop social projects. This concept called Leverage ${ }^{8}$ describes how to use the impact of popular sport events to communicate about an idea or a concept linked with social aspects. In the case of Social Development, the IOC could use the Olympics and all of the major sport events to promote the

\footnotetext{
${ }^{8}$ Strategy which consist at using major sport events to promote social values and ideas in order to communicate about it.
} 
Sport as a tool. It is important and interesting to notice that the International Olympic Committee is now supposed to be very careful during the Olympic attribution about the Legacy after the event with the utilization of the facilities for the local population who cannot have access to the sport equipment. This aspect can be criticized for instance because of the situation in Rio after the 2016 Olympic Games which is worse than before with vandalism, damaged equipment, and an Olympic Park abandoned entirely. This situation shows the lack of governance from the IOC and exposes the limits of the new commission and its next possible weaknesses. Despite these weaknesses, it is essential to give a chance to the organization to build a strong project and also participate as a partner with new initiatives like the Sporting Chance Forum which was organized in Geneva on the $30^{\text {th }}$ of November 2017. All of the principal actors of Sport and Human Rights including the IOC announced the creation of an independent Centre for Sport \& Human Rights during 2018. This project will include governments (USA, Switzerland), major organizations in the sport field (IOC, FIFA, UEFA), companies (Adidas group, Coca-Cola company) but also different offices of the United Nations (UNICEF, UNHCR). This project will be managed by the experienced Mary Robinson who was the first female president of Ireland during more than six years (1990-1997) and also a member of the UNHCR during five years (1997-2002). This recent announcement is for sure a positive way to rediscover strong governance with definite positions and projects. Every innovation and project will allow to reach new beneficiaries and give them the opportunity to develop their skills, knowledge, and competencies through programs designed for them with for global opportunity the increasing of Human Right in the worldwide society. Concerning this Centre for Sport and Human Rights, the idea is to bring together diverse actors from different backgrounds to work as one organization for the same cause. Even if the fields of the different organizations are different, their common work to promote Human Rights through Sport values will have for ambition to create better equality for Human Dignity, Human Rights as well as the labor Rights. It represents a massive opportunity for many beneficiaries all over Europe but also in the World to receive help for their personal development. This initiative is the perfect example that shows that the organizations are aware that, alone, their power is reduced and the association of different stakeholders is a chance for all to reach a higher audience with a more significant impact. It is also interesting to notify that the alliance concerns the different sectors with private companies, non-governmental organization but also governments which allow them to reach different target groups. The Sport will be for all of these organization a tool to reach the goal of giving the same Rights for each Human on the planet.

\section{References}

Office of the Special Adviser to the UN Secretary-General on Sport for Development and Peace (2006). International Year of Sport and Physical Education 2005.

United Nations (2003). Sport for Development and Peace: Towards Achieving the Millenium Development Goals. United Nations $(2001,2003,2010,2016)$. Resolution adopted by the General Assembly.

Sporting Chance Forum (2017). Joint Statement / Diverse Coalition Commits to Establishing Centre for Sport \& Human Rights in 2018.

United Nations Office on Sport for Development and Peace (2014, 2015). Annual report.

United Nations Office on Sport for Development and Peace (2015). Sport and the Sustainable Development Goals.

United Nations Office on Sport for Development and Peace (2011). Achieving the Objectives of the United Nations through Sport.

United Nations Office on Sport for Development and Peace (2016). Youth Leadership Programme booklet.

UN Inter-agency task force (2003). Sport as a Tool for Development and Peace: Towards achieving the United Nations Millenium Goals.

International Sport and Culture Association (2013). MOVE And LEARN.

Ben Sanders (2016). An own goal in sport for development: Time to change the playing field. Volume 4 Issue 6.

Fred Coalter (2010). Sport-for-development impact study.

Fred Coalter (2006). Sport-in-Development: A Monitoring and Evaluation Manual. 
Simon C. Darnell and Lyndsay M.C. Hayhurst (2013). De-Colonising the Politics and Practice of Sport-for-Development: Critical Insights from Post-Colonial Feminist Theory and Methods.

Douglas Hartmann and Christina Kwauk (2011). Sport and Development: An Overview, Critique, and Reconstruction.

Marijke Taks, Laura Misener, Laurence Chalip, B. Christine Green (2013). Leveraging sport events for participation.

\section{Corresponding author:}

Niels de Fraguier

email: niels.defraguier@outlook.fr

phone: +33623115879

Terez korut 9, 1067 Budapest 